\title{
Development of a Comprehensive Software Application for Calculations in Nuclear Medicine and Radiopharmacy
}

\author{
Jesús Luis Gómez Perales ${ }^{1}$ and Antonio García Mendoza ${ }^{2}$ \\ ${ }^{I}$ Nuclear Medicine Service, “Puerta del Mar” University Hospital, Cádiz, Spain; and ${ }^{2}$ Nuclear Medicine Service, "Torrecárdenas" \\ Hospital, Almería, Spain
}

\begin{abstract}
In the daily practice of in-hospital or centralized radiopharmacies, there is a need to perform reliable numeric calculations. Furthermore, several nuclear medicine diagnostic tests also involve carrying out calculations. In both cases, these calculations are sometimes complex or tedious and prone to error. We report the development of a computer software program that performs a comprehensive range of calculations required in radiopharmacy and nuclear medicine diagnostic tests. Methods: This software was developed and compiled in the Visual Basic programming language using algorithms and methods reflected in the scientific literature. Results: We developed 2 versions of the software program, which we call Nucleolab. It automatically performs calculations relating to radiopharmacy practice as well as 9 diagnostic nuclear medicine tests. The 0.1 version performs all these calculations, and the 1.2 version also has a database that enables the user to save and recover diagnostic test results and issue custom reports. The software can be downloaded at www.radiofarmacia.org/ nucleolab-english.Conclusion: To our knowledge, ours is the first attempt to develop a comprehensive software application that facilitates calculations in nuclear medicine and radiopharmacy, reducing errors and improving efficiency and accuracy.
\end{abstract}

Key Words: nuclear medicine software; radiopharmacy software; pediatric dosage of radiopharmaceuticals; $99 \mathrm{mTc}$ generator; red cell volume; plasma volume; red cell kinetic; platelet kinetic; renal plasma flow; glomerular filtration rate

J Nucl Med Technol 2010; 38:153-162

DOI: $10.2967 /$ jnmt.110.075333

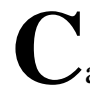

alculations- such as the appropriate pediatric dose of radiopharmaceuticals or the theoretic activity of a ${ }^{99 \mathrm{~m}} \mathrm{Tc}$ generator at any specified time point-are required in radiopharmacy but can be cumbersome and prone to error. There are also several diagnostic techniques in nuclear

\footnotetext{
Received Jan. 21, 2010; revision accepted May 18, 2010.

For correspondence or reprints contact: Jesús Luis Gómez Perales, Nuclear Medicine Service, "Puerta del Mar" University Hospital, Avenida Ana de Viya 21, 11009 Cádiz, Spain.

E-mail: jesusl.gomez.sspa@juntadeandalucia.es

COPYRIGHT @ 2010 by the Society of Nuclear Medicine, Inc.
}

medicine, such as studies of red cell and platelet kinetics, blood volume, or renal function, that require complex or time-consuming calculations. All such calculations can be performed using scientific calculators or spreadsheets. The purpose of this work was to develop a software application, which we call Nucleolab, to perform the most important calculations relating to the practice of radiopharmacy and several important diagnostic techniques of nuclear medicine. In addition, we set out to link this software with a database to store test data and results and to enable the issuance of custom reports of these tests at any time.

\section{MATERIALS AND METHODS}

The first stage in the design of the application was the analysis, in our respective radiopharmacies and nuclear medicine departments, of those processes involving calculations that are of some complexity or are time-consuming. After identifying these processes, we reviewed the scientific literature to find the best ways to perform the calculations. When multiple formulas were described, we tried to choose those most widely agreed upon. These algorithms and methods were used to program the calculations in the software. The computer application was developed and compiled in the Visual Basic programming language (version 6.0; Microsoft) and contains over 300 pages of source code. The installation program was made with Visual Studio Installer (Microsoft). Excel spreadsheets (Microsoft) were used to verify that the program had correctly executed all calculations.

The equations we selected for the calculations are described in the following sections.

\section{Radioactive Decay}

Radioactive decay is important in work with radiopharmaceuticals and is calculated by the standard radioactive decay formula:

$$
\mathrm{A}=\mathrm{A}_{0} \mathrm{e}^{-\lambda \mathrm{t}} \text { or } \mathrm{A}=\mathrm{A}_{0} \mathrm{e}^{\left(-\mathrm{t} \ln 2 / \mathrm{T}_{1 / 2}\right)}
$$

where $\mathrm{A}$ is the activity at any specified time $(\mathrm{t}), \mathrm{A}_{0}$ is the initial activity (when $t=0$ ), $\lambda$ is the decay constant of the 
isotope, and $\mathrm{T}_{1 / 2}$ is the physical half-life of the radionuclide.

\section{Pediatric Dosage}

Several methods to calculate the activity of pediatric doses of radiopharmaceuticals can be found in the scientific literature. We chose the following method:

Pediatric dose $=$ pediatric dose fraction $\times$ adult dose,

where the pediatric dose fraction is calculated as the ratio between body surface area and the average body surface area of adults $\left(1.73 \mathrm{~m}^{2}\right)$. Body surface area $(\mathrm{S})$ is calculated using the Du Bois formula (1):

$$
\mathrm{S}\left(\mathrm{m}^{2}\right)=\text { weight }(\mathrm{kg})^{0.425} \cdot \text { height }(\mathrm{cm})^{0.725} \cdot 0.007184
$$

Moreover, $\mathrm{S}$ can be estimated from weight only (2), using $\mathrm{S}\left(\mathrm{m}^{2}\right)=$ weight $(\mathrm{kg})^{0.7 / 11}$.

More recently, the Dosimetry and Pediatrics Committees of the European Association of Nuclear Medicine (EANM) proposed the use of 2 tables for the calculation of pediatric dose (3). Our software automatically performs the calculations of this new dosage card.

\section{9mTc-Albumin Macroaggregate Dosage}

The volume and activity that should be added to a vial of macroaggregated albumin (MAA) for labeling, depending on the number of particles and the activity of a dose of 99m Tc-MAA, are calculated as follows:

$$
\begin{aligned}
\text { Labeling volume }= & \text { (vial particle number/dose particle number }) \\
& \text { dose volume }
\end{aligned}
$$

Labeling activity $=($ dose activity/dose volume $)$ labeling volume.

The concentration of particles of ${ }^{99 \mathrm{~m}} \mathrm{Tc}-\mathrm{MAA}$ remains constant, but activity decays with time; these calculations should therefore take into account the decay process at any time using the standard radioactive decay formula.

\section{Multiple-Dose Withdrawal from Vials}

Because the radioactive concentration decreases over time, the dose volume required to administer a particular activity increases over time. Knowing the initial activity in the vial, the initial volume in the vial, and the volume and timing of every dose withdrawn from the vial, one can use the standard radioactive decay formula to determine at any time the activity remaining in the vial and the volume needed to obtain a dose of the required activity.

\section{${ }^{99} \mathrm{Mo} /{ }^{99 m T c}$ Generator}

The activity of ${ }^{99} \mathrm{Mo}$ in the generator at any time is calculated by the standard radioactive decay formula. The theoretic activity of ${ }^{99 \mathrm{~m}} \mathrm{Tc}$ in the eluate at any time is calculated using the following equation:

$$
\mathrm{A}_{99 \mathrm{mTc}}=\mathrm{A}_{99 \mathrm{Mo}} 0.86 \lambda_{2}\left[\mathrm{e}^{-\lambda_{1} \mathrm{t}}-\mathrm{e}^{-\lambda_{2} \mathrm{t}}\right] /\left[\left(\lambda_{2}-\lambda_{1}\right) \mathrm{e}^{-\lambda_{1} \mathrm{t}}\right],
$$

where $\lambda_{1}$ and $\lambda_{2}$ represent the decay constants for ${ }^{99} \mathrm{Mo}$ and ${ }^{99 \mathrm{~m}} \mathrm{Tc}$, respectively, and $\mathrm{t}$ is the time between 2 consecutive elutions.

The elution efficiency is the ratio between the measured activity and the theoretic activity, and the specific activity of the eluate is calculated using the following equations:

$$
\begin{gathered}
\text { Specific activity }=\mathrm{A}_{0} / \mathrm{m}_{\mathrm{Tc}} \\
\mathrm{m}_{\mathrm{Tc}}=1.9 .10^{-4} \mathrm{~A}_{0} / \mathrm{h}(\mathrm{t}) \\
\mathrm{h}(\mathrm{t})=\lambda_{1}\left(\mathrm{e}^{-\lambda_{1} \mathrm{t}}-\mathrm{e}^{-\lambda_{2} \mathrm{t}}\right) /\left[1.162\left(\lambda_{2}-\lambda_{1}\right)\left(1-\mathrm{e}^{-\lambda_{1} \mathrm{t}}\right)\right],
\end{gathered}
$$

where $\mathrm{m}_{\mathrm{Tc}}$ is the mass of both ${ }^{99 \mathrm{~m}} \mathrm{Tc}$ and ${ }^{99} \mathrm{Tc}$ (in $\mu \mathrm{g}$ ), $\mathrm{A}_{0}$ is the activity of ${ }^{99 \mathrm{~m}} \mathrm{Tc}$ (in $\mathrm{mCi}$ ), and $\lambda_{1}$ and $\lambda_{2}$ are the decay constants for ${ }^{99} \mathrm{Mo}$ and ${ }^{99 \mathrm{~m}} \mathrm{Tc}$, respectively.

\section{Preparation of Solutions}

The concentration of chemical solutions can be expressed several different ways. We have selected that which is most common in radiopharmacy. Molarity is the number of moles of solute per liter of solution. Percentage composition by mass is the mass of solute divided by the mass of solution (mass of solute plus mass of solvent), multiplied by 100 . Concentration is also frequently expressed as mass of solute divided by volume of solvent $(\mathrm{g} / \mathrm{L}, \mathrm{mg} / \mathrm{L}$, or $\mu \mathrm{g} / \mathrm{L}$ ).

\section{Centrifugation Speed}

The relation between the relative centrifugal acceleration (RCA), measured in $g$; the rotation speed $(v)$, measured in revolutions per minute; and the rotational radius (r), measured in in centimeters, is given by the formula RCA = $0.000011189 \cdot \mathrm{r} \cdot v^{2}$.

\section{Platelet Kinetics and Red Cell Kinetics}

In platelet kinetic studies, it is necessary to calculate the time required for half the labeled platelets to leave the circulation (half-life, or $\mathrm{T}_{1 / 2}$ ), the percentage of platelets destroyed per day (by phagocytosis in the spleen), the mean platelet life span (T), and the recovery. These parameters can be calculated by applying a linear model, an exponential model, or the weighted average of both functions $(4,5)$ :

$$
\text { Percentage platelets destroyed } / \mathrm{d}=100 / 2 \mathrm{~T}_{1 / 2} \text {. }
$$

The linear regression function $A_{L}(t)$ is calculated by:

$$
\begin{aligned}
\mathrm{A}_{\mathrm{L}}(\mathrm{t}) & =\mathrm{A}_{\mathrm{L}}(0)-a \mathrm{t} \\
\mathrm{T}_{\mathrm{L}} & =\mathrm{A}_{\mathrm{L}}(0) / a,
\end{aligned}
$$

where $\mathrm{A}_{\mathrm{L}}(0)$ is the $y$-intercept, $a$ is the rate of platelet disappearance, and $T_{L}$ is the mean platelet life span. 
The exponential regression function $A_{E}(t)$ is calculated by:

$$
\begin{aligned}
\mathrm{A}_{\mathrm{E}}(\mathrm{t}) & =\mathrm{A}_{\mathrm{E}}(0) \mathrm{e}^{-\mathrm{kt}} \\
\mathrm{T}_{\mathrm{E}} & =1 / \mathrm{k},
\end{aligned}
$$

where $\mathrm{A}_{\mathrm{E}}(0)$ is the $y$-intercept, $\mathrm{k}$ is the relative rate of platelet disappearance, and $\mathrm{T}_{\mathrm{E}}$ is the mean platelet life span.

The weighted mean regression function $A_{W}(t)$ is calculated by:

$$
A_{W}(t)=\left[S_{E} H_{L}(t)+S_{L} H_{E}(t)\right] /\left(S_{E}+S_{L}\right)
$$

where $S_{L}$ and $S_{E}$ are the residual sum of squares associated with linear and exponential regression curves:

$$
\mathrm{S}_{\mathrm{L}}=\sum\left[\left(\mathrm{H}_{\mathrm{L}}\right)_{\mathrm{i}}-\mathrm{N}_{\mathrm{i}}\right]^{2} \text { and } \mathrm{S}_{\mathrm{E}}=\sum\left[\left(\mathrm{H}_{\mathrm{E}}\right)_{\mathrm{i}}-\mathrm{N}_{\mathrm{i}}\right]^{2}
$$

where $\left(\mathrm{H}_{\mathrm{L}}\right)_{\mathrm{i}}$ and $\left(\mathrm{H}_{\mathrm{E}}\right)_{\mathrm{i}}$ are linear and exponential regression curve points corresponding to data $\mathrm{N}_{\mathrm{i}}$.

The weighted mean platelet life span is calculated by:

$$
\mathrm{T}_{\mathrm{W}}=\left(\mathrm{S}_{\mathrm{E}} \mathrm{T}_{\mathrm{L}}+\mathrm{S}_{\mathrm{L}} \mathrm{T}_{\mathrm{E}}\right) /\left(\mathrm{S}_{\mathrm{E}}+\mathrm{S}_{\mathrm{L}}\right) .
$$

The recovery is the percentage of activity bound to platelets that is circulating at a given time $t$ (usually at time 0 ) and is obtained by dividing the current activity at time $t$ by managed total activity.

In red cell kinetic studies, it is necessary to calculate the time taken for half the labeled red cells to leave the circulation $\left(\mathrm{T}_{1 / 2}\right)$ and the percentage of erythrocytes destroyed every day. These parameters can be calculated using a linear model, an exponential model, or the weighted average of both (6). The calculations are performed in the same way as described for platelet kinetics. However, in this case, ${ }^{51} \mathrm{Cr}$ is eluted at a rate that significantly affects estimates of mean red cell life span. The average elution of chromium is $1 \%$ per day, which is of the same magnitude as the normal rate of red cell destruction. Accordingly, an appropriate correction factor (f) must be applied to the radioactive concentration of the blood specimens, to offset this effect of elution of ${ }^{51} \mathrm{Cr}$ :

$$
f=0.0005 t+1.0178
$$

where $\mathrm{t}$ is in hours.

\section{Red Cell Volume and Plasma Volume}

The calculations relating to measurement of red cell volume, using sodium ${ }^{51} \mathrm{Cr}$-radiochromate as a red cell label, and the calculations relating to measurement of plasma volume, using radioiodine ${ }^{125} \mathrm{I}$-labeled human serum albumin as a plasma label, are according to the recommendations of the International Council for Standardization in Hematology (7).
If red cell volume with ${ }^{51} \mathrm{Cr}$-radiochromate as the red cell label is calculated by:

$$
\mathrm{RCV}=\mathrm{S} \mathrm{R} \mathrm{V} \mathrm{sd}_{\mathrm{v}} / \mathrm{B},
$$

then blood volume and plasma volume can be calculated by:

$$
\mathrm{BV}=\mathrm{RCV} /\left(\mathrm{f} \mathrm{H}_{\mathrm{v}}\right) \text { and } \mathrm{PV}=\mathrm{BV}-\mathrm{RCV} \text {. }
$$

If plasma volume with ${ }^{125}$ I-human serum albumin can be calculated by:

$$
\mathrm{PV}=\mathrm{SRV}_{\mathrm{sd}} / \mathrm{P}_{0}
$$

then blood volume and red cell volume can be calculated by:

$$
\mathrm{BV}=\mathrm{PV} /\left[1-\left(\mathrm{f} \mathrm{H}_{\mathrm{v}}\right)\right] \text { and } \mathrm{RCV}=\mathrm{BV}-\mathrm{PV},
$$

where RCV is red cell volume, $\mathrm{S}$ is concentration of radioactivity in a diluted standard (in cpm/mL), $\mathrm{R}$ is ratio between amount of labeled red cell suspension injected and amount of labeled red cell suspension (both in g) added to the volumetric flask in which the diluted standard is prepared, $\mathrm{V}_{\mathrm{sd}}$ is standard dilution volume (in $\mathrm{mL}$ ), $\mathrm{H}_{\mathrm{v}}$ is venous hematocrit, $\mathrm{B}$ is concentration of radioactivity in the blood sample withdrawn when mixing of the radiopharmaceutical in the bloodstream has been completed (in cpm/ $\mathrm{mL}$ of blood), BV is blood volume, $\mathrm{f}$ is $\mathrm{H}_{\mathrm{b}} / \mathrm{H}_{\mathrm{v}}\left(\mathrm{H}_{\mathrm{b}}\right.$ is wholebody hematocrit), $\mathrm{PV}$ is plasma volume, and $\mathrm{P}_{0}$ is concentration of radioactivity in the plasma sample $(\mathrm{cpm} / \mathrm{mL})$ corrected to zero time by extrapolation of 3 samples to the $y$-axis after the concentration in each has been plotted against time on semilog paper. The average $f$ value is usually taken as 0.9 . However, there is a wide deviation from this mean value, both in healthy subjects and in patients with various conditions (notably in cases of splenomegaly).

The red cell volume and plasma volume reference values are calculated according to the expert panel of radionuclides of the International Council for Standardization in Hematology (8):

$$
\begin{aligned}
& \text { For males: } \mathrm{RCV}=1486 \mathrm{~S}-825 \text { and } \mathrm{PV}=1578 \mathrm{~S} \\
& \text { For females: } \mathrm{RCV}=1.06 \mathrm{~A}+822 \mathrm{~S} \text { and } \mathrm{PV}=1395 \mathrm{~S} \text {, }
\end{aligned}
$$

where S represents body surface area (in $\mathrm{m}^{2}$ ) according the $\mathrm{Du}$ Bois formula and $\mathrm{A}$ is age (in $\mathrm{y}$ ).

\section{Effective Renal Plasma Flow}

The curve for plasma ${ }^{131}$ I-sodium iodohippurate concentration versus time is obtained using a 2-compartment model proposed by Sapirstein $(9,10)$. The initial rapid-disappearance "fast curve" reflects the distribution of ${ }^{131}$ I-sodium iodohippurate in the extravascular compartment and is followed by a slow-disappearance "slow curve" that represents renal elimination. The plasma concentration-versus-time data after injection are analyzed using the following equations: 
Fast exponential: $A_{F}(t)=A_{F} \exp \left(-k_{F} t\right)$ and $\left(T_{1 / 2}\right)_{F}=1 / k_{F}$,

where $A_{F}(t)$ is the exponential regression for the fast curve, $\mathrm{A}_{\mathrm{F}}$ is the $y$-intercept of the fast exponential, $\mathrm{k}_{\mathrm{F}}$ is the relative plasma clearance rate of ${ }^{131}$ I-sodium iodohippurate, and $\left(\mathrm{T}_{1 / 2}\right)_{\mathrm{F}}$ is the time required for half the ${ }^{131} \mathrm{I}$-sodium iodohippurate to leave the circulating plasma according to the fast curve.

$$
\text { Slow exponential: } A_{S}(t)=A_{S} \exp \left(-k_{S} t\right) \text { and }\left(T_{1 / 2}\right)_{S}=1 / k_{S} \text {, }
$$

where $A_{s}(t)$ is the exponential regression for the slow curve, $A_{S}$ is the $y$-intercept of the fast exponential, $\mathrm{k}_{\mathrm{S}}$ is the relative plasma clearance rate of ${ }^{131} \mathrm{I}$-sodium iodohippurate, and $\left(\mathrm{T}_{1 / 2}\right)_{\mathrm{S}}$ is the time required for half the ${ }^{131} \mathrm{I}$-sodium iodohippurate to leave the circulating plasma according to the slow curve.

The plasma clearance of ${ }^{131}$ I-sodium iodohippurate is calculated as:

$$
\begin{aligned}
\mathrm{ERPF} & =\mathrm{Ik}_{\mathrm{F}} \mathrm{k}_{\mathrm{S}} /\left(\mathrm{A}_{\mathrm{F}} \mathrm{k}_{\mathrm{F}}+\mathrm{A}_{\mathrm{S}} \mathrm{k}_{\mathrm{S}}\right) \\
& =\mathrm{I} \ln 2 /\left[\mathrm{A}_{\mathrm{F}}\left(\mathrm{T}_{1 / 2}\right)_{\mathrm{F}}+\mathrm{A}_{\mathrm{S}}\left(\mathrm{T}_{1 / 2}\right)_{\mathrm{S}}\right],
\end{aligned}
$$

where ERPF is effective renal plasma flow (in $\mathrm{mL} \cdot \mathrm{min}^{-1}$ ) and $\mathrm{I}$ is the injected dose (in cpm).

\section{Tubular Extraction Rate}

The clearance of ${ }^{99} \mathrm{~m} \mathrm{Tc}-$ mercaptoacetyltriglycine $\left({ }^{99 \mathrm{~m}} \mathrm{Tc}-\right.$ MAG3), also known as tubular extraction rate, is calculated using both the Russell algorithm (11) and the Bubeck algorithm (12). In the Russell algorithm:

MAG3 clearance $=F_{\max }\left(1-\mathrm{e}^{\left(-\alpha\left(1 / \mathrm{c}-\mathrm{V}_{\mathrm{lag}}\right)\right)}\right)(\mathrm{mL} / \mathrm{min})$,

where $c$ is the fraction of dose per liters of plasma $\left(\mathrm{L}^{-1}\right)$, $\mathrm{F}_{\text {max }}$ is $0.04 \mathrm{t}^{2}-8.2 \mathrm{t}+915(\mathrm{~mL} / \mathrm{min}) \quad(\mathrm{t}$ is time between injection and withdrawal of sample [min]), $\alpha$ is $6.5 \cdot 10^{-6}$ $\mathrm{t}^{2}-8.6 \cdot 10^{-4} \mathrm{t}+0.0391\left(\mathrm{~L}^{-1}\right)$, and $\mathrm{V}_{\text {lag }}$ is $-0.0015 \mathrm{t}^{2}+$ $0.01 \mathrm{t}+8.79(\mathrm{~L})$. In the Bubeck algorithm:

$$
\begin{aligned}
\operatorname{TER}(\text { MAG3 })= & \mathrm{A}+\mathrm{B} \times \operatorname{Ln}\left(\mathrm{ID} / \mathrm{Cn}_{\mathrm{t}}\right) \\
& \left(\mathrm{mL} \cdot \mathrm{min}^{-1} \cdot 1.73 \mathrm{~m}^{-2}\right),
\end{aligned}
$$

where TER is tubular extraction rate, $\mathrm{A}$ is $-517 \mathrm{e}^{-0.011 \mathrm{t}}$ $\left(\mathrm{mL} \cdot \mathrm{min}^{-1} \cdot 1.73 \mathrm{~m}^{-2}\right)(\mathrm{t}$ is time between injection and withdrawal of sample [min]), $B$ is $295 \mathrm{e}^{-0.016 \mathrm{t}}\left(\mathrm{mL} \cdot \mathrm{min}^{-1} \cdot 1.73\right.$ $\left.\mathrm{m}^{-2}\right)$, ID is injected dose $(\mathrm{MBq})$, and $\mathrm{Cn}_{\mathrm{t}}$ is normalized plasma concentration at time $\mathrm{t}\left(\%\right.$ dose $\left.\cdot \mathrm{L}^{-1} \cdot 1.73 \mathrm{~m}^{-2}\right)$.

\section{Glomerular Filtration Rate}

Calculations of glomerular filtration rate (GFR) of ${ }^{51} \mathrm{Cr}$-ethylenediamine tetraacetic acid (EDTA) are performed by 3 different methods. In the method of Ham and Piepsz (13):

Dose $=($ standard activity $)($ dose weight $) /($ standard weight $)$.

The distribution volume (in L) at time $\mathrm{t}$ is defined as:

$$
\mathrm{V}_{\mathrm{t}}=\operatorname{dose} / \mathrm{A}_{\mathrm{t}}
$$

The 2-h volume distribution $\left(\mathrm{V}_{120}\right)$ is therefore given by:

$$
\mathrm{V}_{120}=\operatorname{dose} / \mathrm{A}_{120}
$$

where $\mathrm{A}_{120}$ represents the plasma tracer concentration $120 \mathrm{~min}$ after administration of the dose. When the blood sample was not taken exactly at the 120th minute, a small correcting factor was introduced:

$$
\mathrm{A}_{120}=\mathrm{A}_{(\mathrm{t})} \times \mathrm{e}^{(0.008)(\mathrm{t}-120)},
$$

where $t$ is the blood sampling time and $A_{(t)}$ is the plasma concentration at that time. An arbitrary value of $0.008 \mathrm{~min}^{-1}$ is used to replace the biologic decay constant. This value corresponds to the mean value of $\lambda$ observed in the population studied.

$$
\mathrm{GFR}=2.602 \cdot \mathrm{V}_{120}-0.273(\mathrm{~mL} / \mathrm{min})
$$

Normalized GFR $=$ GFR $\cdot 1.73 /$ body surface $\operatorname{area}(\mathrm{mL} / \mathrm{min})$.

In the method of Mistry (14):

Dose $=($ standard activity $)($ dose weight $) /($ standard weight $)$

$$
\mathrm{VD}=\operatorname{dose} /\left(\mathrm{A}_{0} \times 1,000\right),
$$

where VD is the volume of distribution (in $\mathrm{L}$ ) and $\mathrm{A}_{0}$ is the counting rate at time 0 (obtained from intercept at time 0 ).

$$
\mathrm{GFR}=\mathrm{VD} \cdot 0.693 \cdot 0.87 \cdot 1,000 / \mathrm{T}_{1 / 2}(\mathrm{~mL} / \mathrm{min}),
$$

where $\mathrm{T}_{1 / 2}$ is the time when $\mathrm{A}=\mathrm{A}_{0} / 2$, and

$$
\begin{aligned}
\text { Normalized GFR }= & \text { GFR } \cdot 1.73 / \text { body surface area } \\
& \left(\mathrm{mL} \cdot \mathrm{min}^{-1} \cdot 1.73 \mathrm{~m}^{-2}\right) .
\end{aligned}
$$

In the 2-compartment model proposed by Sapirstein $(15,16)$, this calculation is performed in the same way as described above for effective renal plasma flow:

$$
\begin{aligned}
& \text { Fast exponential: } A_{F}(t)=A(0) e^{-k_{F} t} \\
& \text { Slow exponential: } A_{S}(t)=A(0) e^{-k_{S} t} \\
& \begin{aligned}
\text { GFR } & =I k_{F} k_{S} /\left(A_{F} k_{F}+A_{S} k_{S}\right) \\
& =I \ln 2 /\left[A_{F}\left(T_{1 / 2}\right) F+A_{S}\left(T_{1 / 2}\right)_{S}\right] .
\end{aligned}
\end{aligned}
$$

\section{RESULTS}

\section{Dosimetry}

Nucleolab has 2 screens for calculating pediatric doses of radiopharmaceuticals. One calculates pediatric doses from the weight and height of the child (or only by weight) and from the standard adult dosage. The other calculates pediatric doses from the patient's weight and the radiopharmaceutical, 
according to the EANM 2007 pediatric dosage card (Fig. 1).

The "99m Tc-MAA dosage" screen for calculations relating to the preparation and withdrawal of $99 \mathrm{~m}$ Tc-MAA consists of 3 subscreens. The "vial labeling" subscreen calculates the labeling volume and labeling activity when the following data are entered: dose activity, dose volume, number of particles in the dose, number of particles in the vial, and time between labeling and withdrawal of the dose. The "dose dispensation" subscreen (Fig. 2) calculates the dose volume and dose activity when the following data are entered: labeling activity, labeling volume, number of particles in the dose, number of particles in the vial, and time between labeling and withdrawal of the dose. The "particle number" subscreen calculates the volume and the number of particles in the dose when the following data are entered: labeling activity, labeling volume, dose activity, number of particles in the vial, and time between labeling and withdrawal of the dose.

The "dose withdrawal" screen calculates the volume of each dose according to activity, half-life of the radionuclide (which the user can select from a combination box with 48 radionuclides), time of dose withdrawal, initial activity and initial volume in the vial, and activity of any doses previously withdrawn. This screen also calculates the remaining activity and volume of radiopharmaceutical in the vial at any time (Fig. 3).

\section{Radiopharmacy}

The "radioactive decay calculator" screen contains a combination box allowing the user to select from among the 48 radionuclides included in the database. If the radionuclide of interest is not included, the user can manually enter the physical half-life. The radioactive decay is calculated according to the standard radioactive decay formula.

The "99 Mo/ ${ }^{99 m}$ Tc generator" screen calculates the activity of ${ }^{99} \mathrm{Mo}$ and ${ }^{99 \mathrm{~m} \mathrm{Tc}}$ in the generator at any time, the activity eluted according to the elution efficiency or vice versa, the specific activity, and the masses of ${ }^{99 \mathrm{~m}} \mathrm{Tc}$ and ${ }^{99} \mathrm{Tc}$ in the eluate (Fig. 4). The user has to input the calibrated activity, date and time of calibration, date and time of elution, and date and time of the previous elution.

The "solutions assistant" screen performs calculations relating to preparation of solutions. This screen calculates the amount of solute required to prepare a solution, depending on the desired concentration in different units, as well as the amount of a concentrated solution required to prepare a more diluted solution. The solute can be entered in the screen by its molecular formula or by its molecular mass.

The "centrifuge" screen automatically converts rpm to $g$ and vice versa according to the radius of a centrifuge (in $\mathrm{cm}$ ).

\section{Diagnostic Tests}

The "red cell survival" screens calculate the half-life and percentage of erythrocytes destroyed every day. The calculations use a linear model, an exponential model, and the weighted average of both models, as well as the regression coefficients of both the linear function and the exponential function. These screens include a minimum of 6 specimens and a maximum of 12 specimens (Fig. 5). The user has to enter the radioactive concentration, the times of blood specimen withdrawal, and the background radioactivity if necessary.

The "platelet survival" screens calculate the half-life and the percentage of platelets destroyed per day, the mean platelet life span, and the recovery $($ at $\mathrm{t}=0)$. The calculations

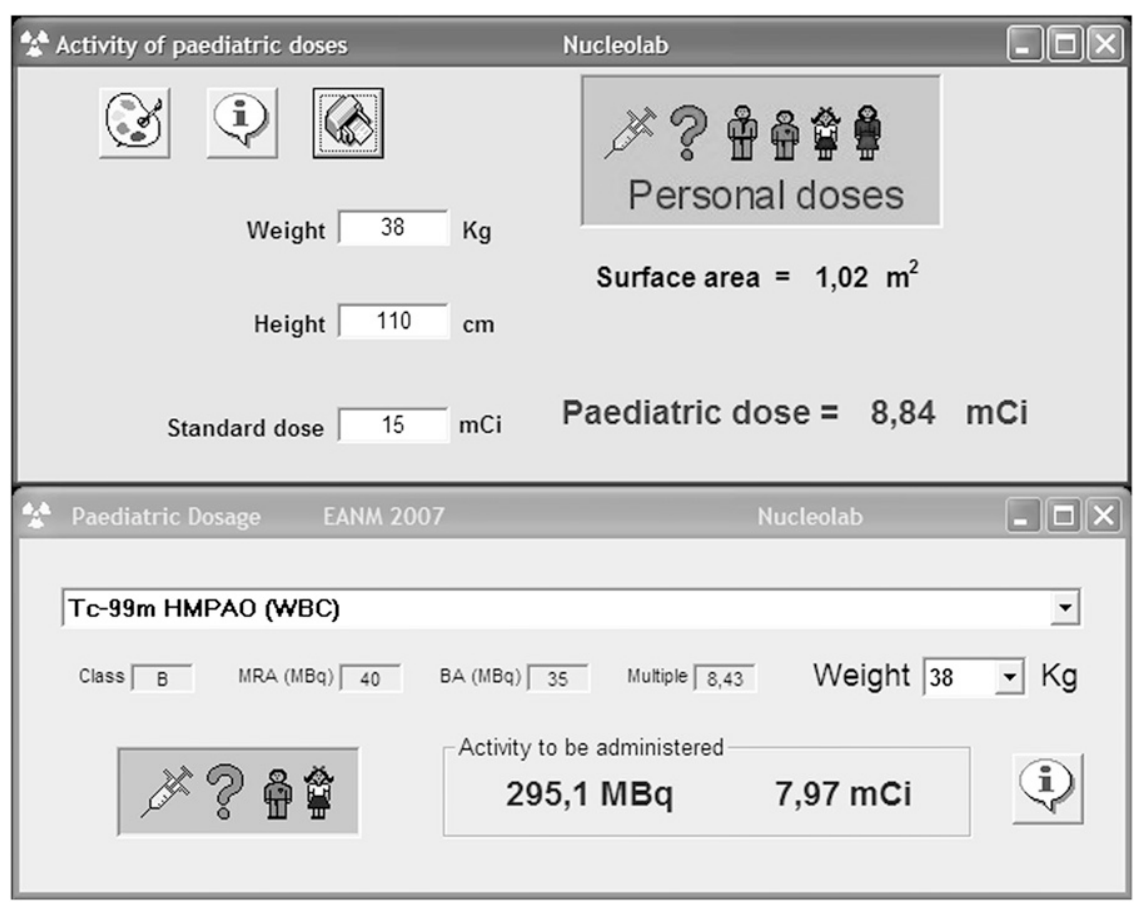

FIGURE 1. Two screens for calculating pediatric doses of radiopharmaceuticals. Top screen calculates pediatric doses from weight and height of child and from adult standard dosage. Bottom screen calculates pediatric doses from patient's weight and radiopharmaceutical, according to EANM 2007 pediatric dosage card. 


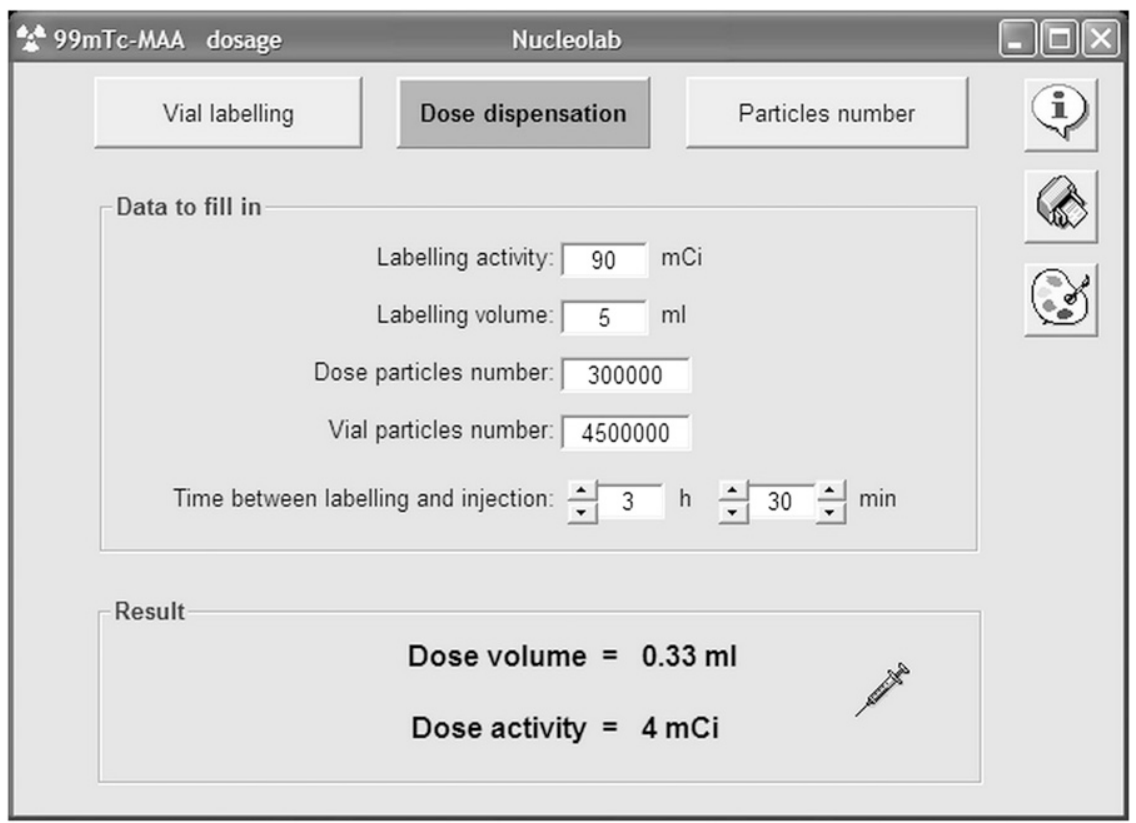

FIGURE 2. 99mTc-MAA dosage.

use a linear model, an exponential model, and the weighted average of both models, as well as the regression coefficients of both the linear function and the exponential function. These screens include calculations for a minimum of 6 specimens and a maximum of 12 specimens. The user has to enter the activity of the dose syringe before and after injection, the activity of the standard syringe before and after the contents are poured into the dilution flask, the volume of the dilution flask, the radioactive concentration of the dilute standard, the venous hematocrit, the radioactive concentration and times of withdrawal of the blood and plasma specimens, and the background radioactivity if necessary.

The "red cell volume" screen calculates the red cell volume from the activity of the dose syringe before and after injection, the activity of the standard syringe before and after its contents are poured into the dilution flask, the volume of the dilution flask, the venous hematocrit, the radioactive concentration of the dilute standard, the background radioactivity if necessary, and the radioactive concentration of the blood specimens withdrawn $30 \mathrm{~min}$ after injection of ${ }^{51} \mathrm{Cr}$-chromate. The screen also calculates blood volume and plasma volume from red cell volume, venous hematocrit, and $\mathrm{f}\left(\mathrm{H}_{\mathrm{b}} /\right.$ $\left.H_{v}=0.9\right)$. Then, it calculates the maximum possible errors when $f$ varies between 0.76 and 1.15. Finally, the screen compares the results for red cell volume, plasma volume, and blood volume with the reference values expected according to the age, height, and weight of the patient (Fig. 6).

The "plasma volume" screen calculates plasma volume from the activity of the dose syringe before and after injection, the activity of the standard syringe before and after its contents are poured into the dilution flask, the volume of

FIGURE 3. Withdrawal of radiopharma-

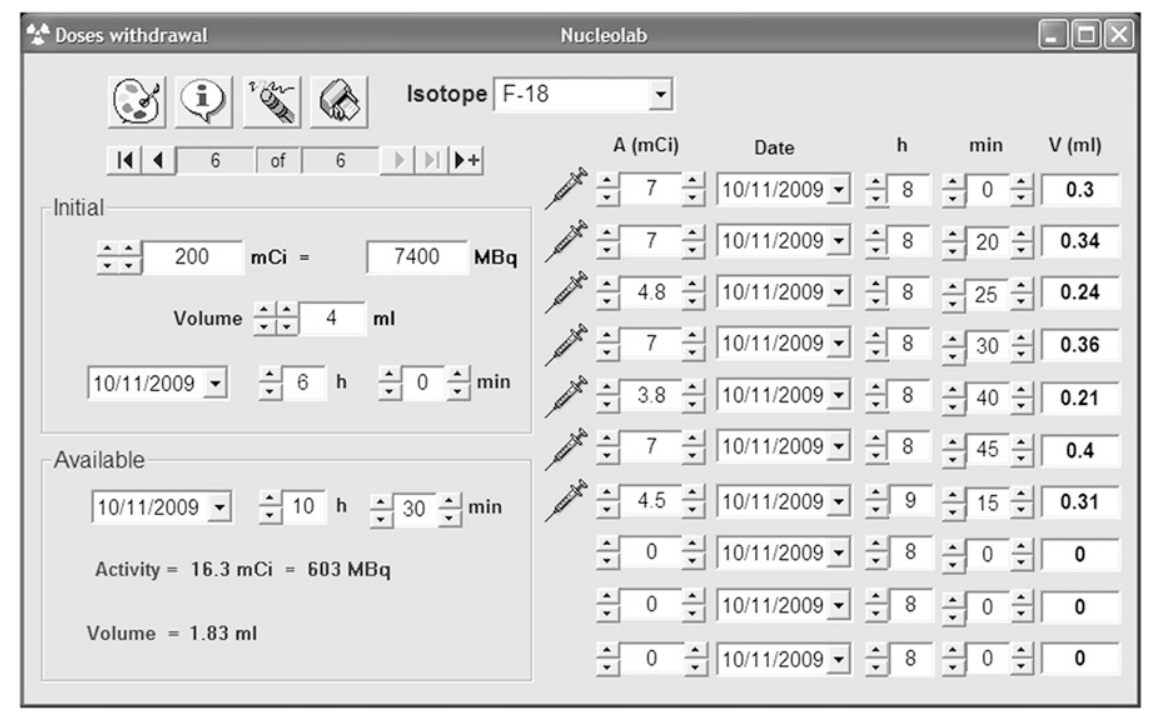




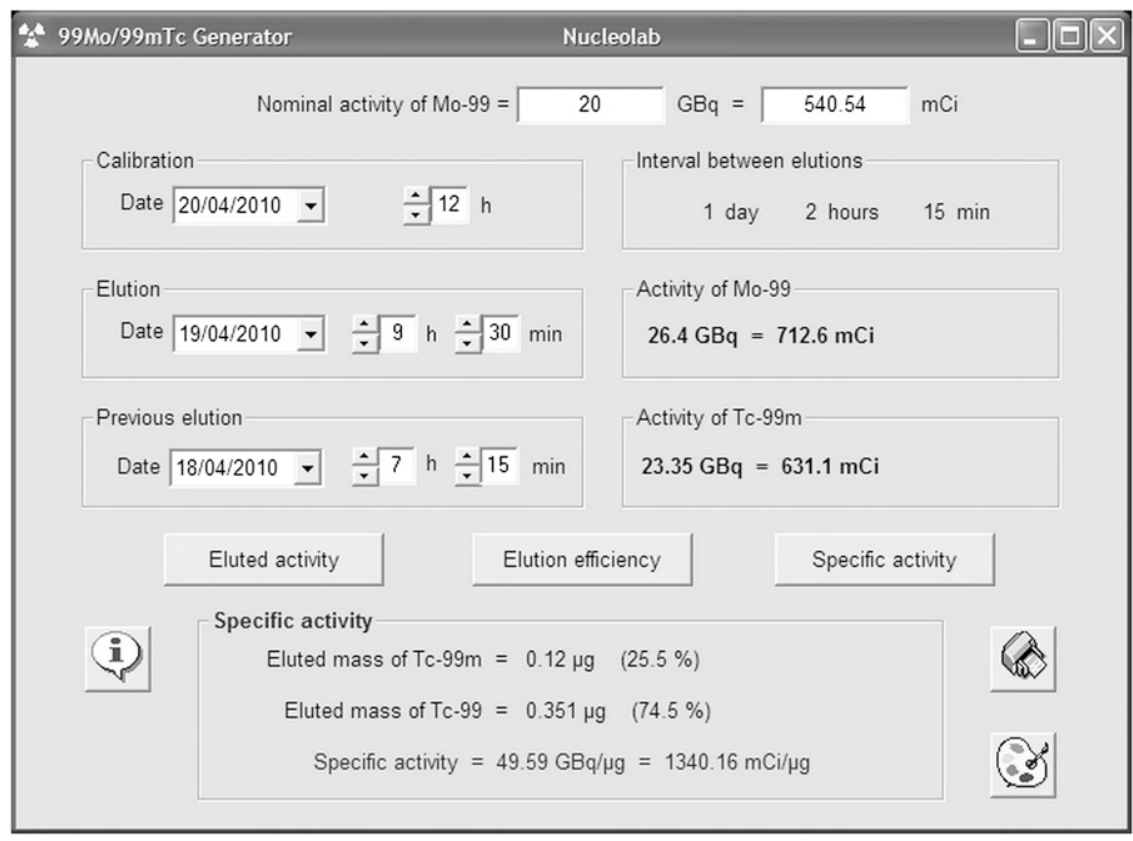

FIGURE 4. ${ }^{99} \mathrm{Mo} / 99 \mathrm{~mm} \mathrm{Tc}$ generator.

the dilution flask, the venous hematocrit, the radioactive concentration of the dilute standard, the background radioactivity if necessary, and the radioactive concentration of the 3 plasma specimens withdrawn at different times after injection of the ${ }^{125}$ I-human serum albumin. The screen also calculates blood volume and red cell volume from plasma volume, venous hematocrit, and $\mathrm{f}\left(\mathrm{H}_{\mathrm{b}} / \mathrm{H}_{\mathrm{v}}=0.9\right)$. Then, it calculates the maximum possible errors when $f$ varies between 0.76 and 1.15. Finally, the screen compares the obtained results for plasma volume, red cell volume, and blood volume with the reference values expected according to the age, height, and weight of the patient.
The "effective renal plasma flow" screen calculates the effective renal plasma flow (and its normalized value) of ${ }^{131}$ I-sodium iodohippurate by the 2-compartment model. The data to be input are the activity of the dose syringe before and after injection, the activity of the standard syringe before and after its contents are poured into the dilution flask, the volume of the dilution flask, the radioactive concentration of the dilute standard, the background radioactivity if necessary, and the radioactive concentration of the 6 plasma specimens withdrawn at different times after injection of the ${ }^{131}$ I-sodium iodohippurate (Fig. 7).

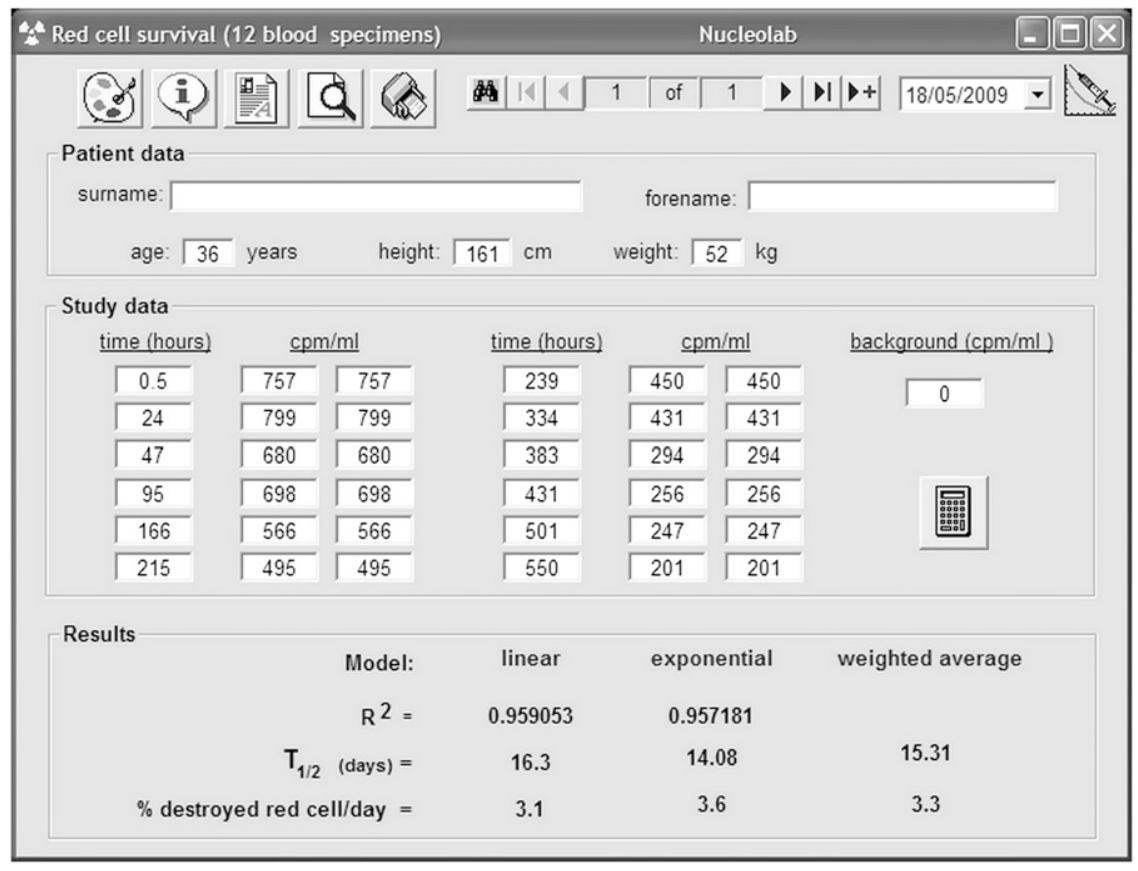

FIGURE 5. Red cell survival. 


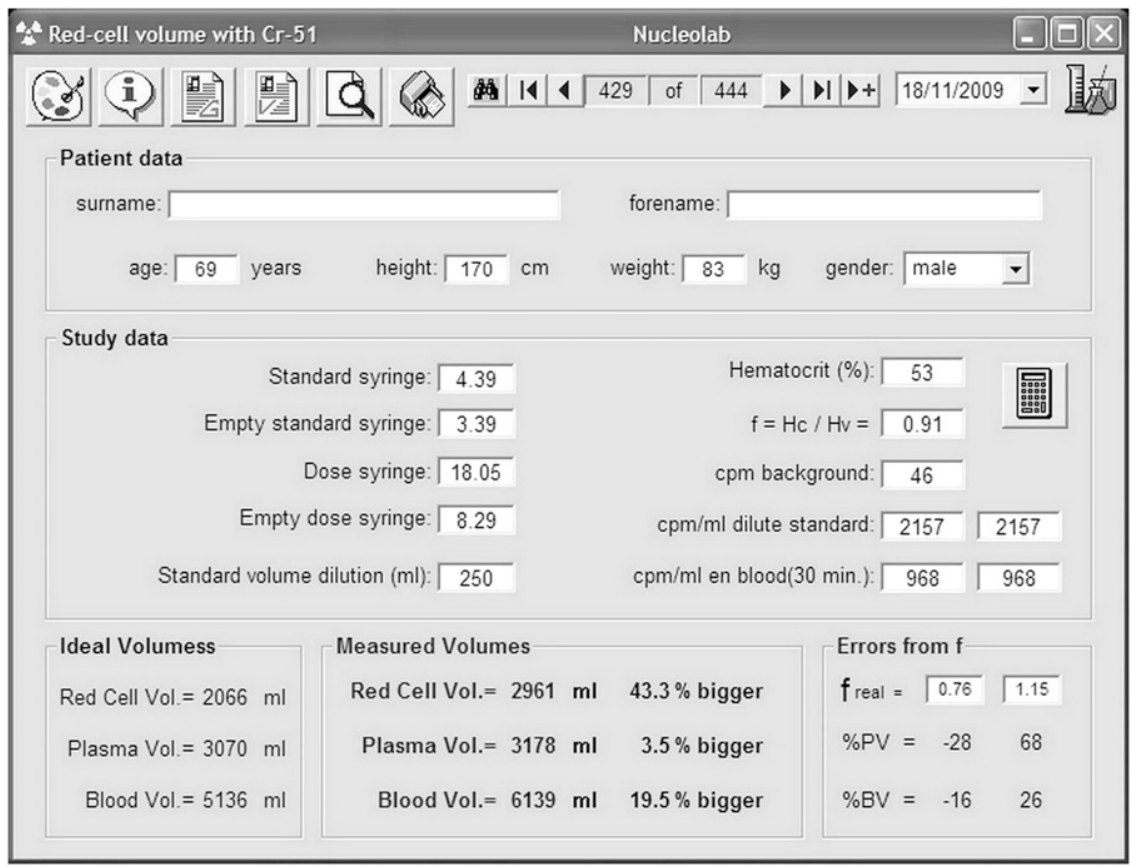

FIGURE 6. Red cell volume.

The "tubular extraction rate" screen calculates the ${ }^{99 \mathrm{~m}} \mathrm{Tc}-$ MAG3 plasma clearance (and its normalized value) from a single specimen using both the Russell algorithm and the Bubeck algorithm. The user has to enter the activity of the dose syringe before and after injection, the activity of the standard syringe before and after its contents are poured into the dilution flask, the time between injection of the dose and withdrawal of the blood specimen, the volume of the dilution flask, the radioactive concentration of the dilute standard, the radioactive concentration of the plasma specimen, and the background radioactivity if necessary.

The "glomerular filtration rate (1 specimen)" screen calculates the GFR (and its normalized value) of ${ }^{51} \mathrm{Cr}$-EDTA by the method of Ham and Piepsz. The data needed are the activity of the dose syringe before and after injection, the activity of the standard syringe before and after the contents are poured into the dilution flask, the time between injection of the dose and withdrawal of the blood specimen, the volume of the dilution flask, the radioactive concentration of the dilute standard, the radioactive concentration of the plasma specimen at about $2 \mathrm{~h}$ after injection of ${ }^{51} \mathrm{Cr}$-EDTA, and the background radioactivity if necessary.

The "glomerular filtration rate (3 specimens)" screen calculates the GFR (and its normalized value) of ${ }^{51} \mathrm{Cr}$ EDTA by the method of Mistry. The user has to enter the activity of the dose syringe before and after injection, the activity of the standard syringe before and after its contents are poured into the dilution flask, the volume of the dilution flask, the radioactive concentration of the dilute standard, the background radioactivity if necessary, and the radioactive concentration of the 3 plasma specimens withdrawn at different times after injection of the ${ }^{51} \mathrm{Cr}$-EDTA.

The "glomerular filtration rate (6 specimens)" screen calculates the GFR (and its normalized value) of ${ }^{51} \mathrm{Cr}$ -
EDTA by a 2-compartment model. The data to be input are the activity of the dose syringe before and after injection, the activity of the standard syringe before and after its contents are poured into the dilution flask, the volume of the dilution flask, the radioactive concentration of the dilute standard, the background radioactivity if necessary, and the radioactive concentration of the 6 plasma specimens withdrawn at different times after injection of the ${ }^{51} \mathrm{Cr}$-EDTA.

To calculate the normalized values of every renal test, one needs to enter the weight, height, and age of the patient in the corresponding screens.

\section{Utilities}

All Nucleolab screens have an "information" button. Clicking on this button provides detailed information about the working protocols, calculation methods, and bibliographic references of the program. The screens also have a button to change the background color. The screens of diagnostic tests allow storage of all data (including remarks) from the tests and recovery of the data through a search window by patient name or date of study. The screens also allow viewing and printing of one or more customized reports for each diagnostic test.

\section{Maintenance}

The "database" screen allows one to network, compress, back up, and retrieve the database. It is important to regularly back up the data using the "copy" button to avoid losing data if Nucleolab needs to be reinstalled on the same computer or is being installed on another computer. Stored data are recovered using the "retrieve" button. Moreover, it is also desirable to regularly compact the database using the "compress" button.

The software can be used in network mode by installing the application on multiple computers and placing the 


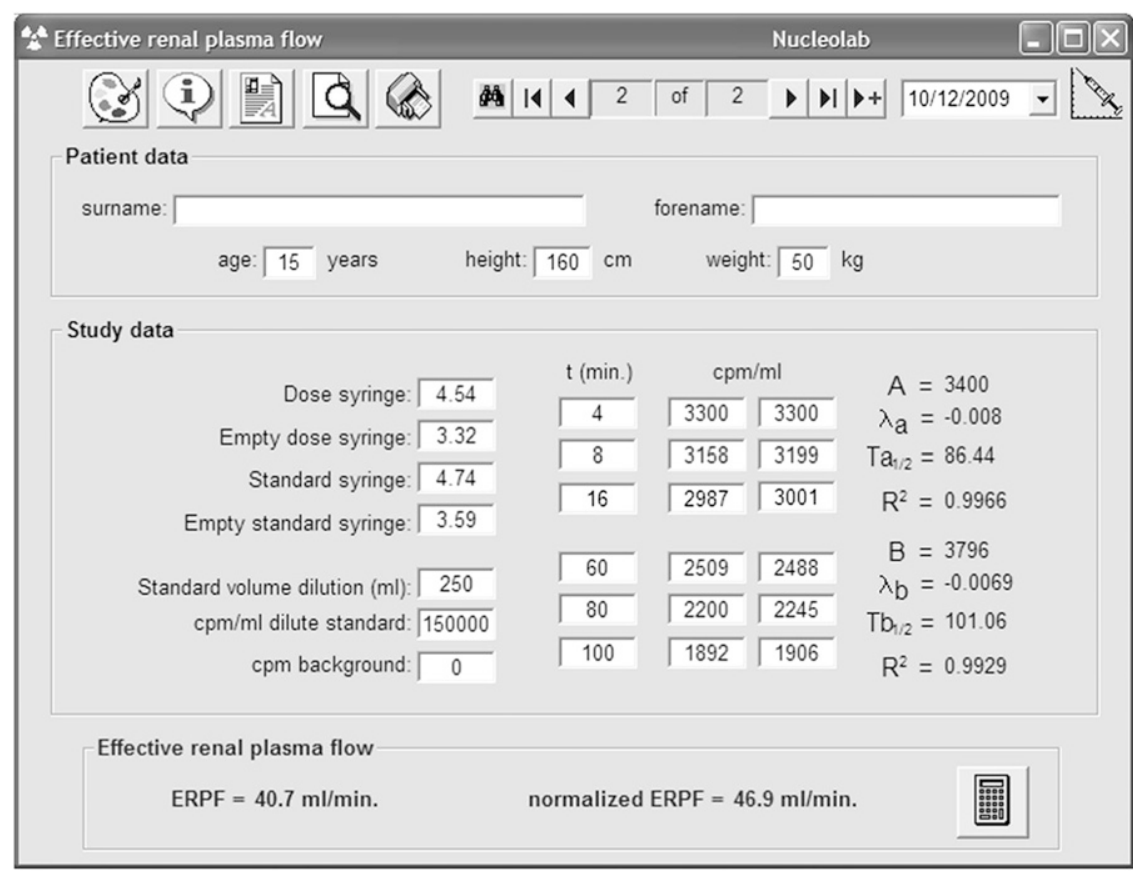

FIGURE 7. Effective renal plasma flow.

"BaseNucleolab.mdb" database file in a directory on a network server. For each installation, this file has to be addressed to the same directory on the network.

The "general data" screen allows the user to adjust the headers and signatures of reports.

\section{Software Requirements}

The minimum technical requirements for installation of Nucleolab version 0.1 are a Microsoft Windows 98 (or more recent) operating system, a 2-GB hard drive (minimally), and $64 \mathrm{MB}$ of RAM memory. Nucleolab version 1.2 additionally requires Microsoft Office 2002 (or more recent) software. The 0.1 version performs all the calculations, and the 1.2 version also has the database that enables users to save and recover diagnostic test results and issue custom reports.

\section{DISCUSSION}

The computer program Nucleolab runs various calculations that are needed in radiopharmacies and nuclear medicine departments, using algorithms and methods described in the scientific literature.

To calculate pediatric dosages, the EANM recommends use of a card consisting of one table showing multiples of the baseline activity and another table showing the recommended activities for 39 procedures. However, the calculations are complex, and the authors of the card suggested that software be introduced to automate the calculations (3). We included such automation in our software, which performs the calculations in a few mouse clicks.

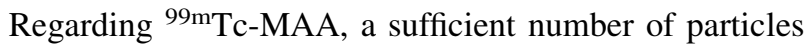
needs to be administered to avoid a nonuniform distribution of radioactivity in the lung. On the other hand, early reports indicated acute toxicity from administering too many particles for lung scans, leading several investigators to try to determine the ideal number of particles for a satisfactory lung scan (17). Consequently, calculations related to the preparation and withdrawal of ${ }^{99 \mathrm{~m}}$ Tc-MAA are important. These calculations can be performed quickly and reliably using the "99m Tc-MAA dosage" screen.

Because radioactive concentration decreases over time, it is helpful to be able determine at any one time the activity remaining in a vial of radiopharmaceutical, as well as the volume that contains the activity required for a dose. With the help of the "dose withdrawal" screen, radiopharmacists and technologists may withdraw more accurate doses at the first attempt, reducing deterioration of the rubber septum, protecting the integrity of the contents of a typical multidose preparation (quality and patient safety improvement), and reducing exposure of the operator's fingers to radiation (occupational health and safety improvement).

The data sheets of ${ }^{99 m} \mathrm{Tc}$ generators include nomograms (18) and tables to facilitate the complex calculations involved. Nucleolab provides an easier way to compute the amount of ${ }^{99 \mathrm{~m}} \mathrm{Tc}$ available at any time after elution, as well as other parameters of interest, such as the elution efficiency or the specific activity of the eluate.

Some nuclear medicine diagnostic tests require calculations that normally are time-consuming and error-prone but, with the help of Nucleolab, can be accomplished quickly and reliably. Furthermore, the screens of Nucleolab are linked to a database enabling data recovery and the issuance of custom reports.

\section{CONCLUSION}

To our knowledge, Nucleolab is the first attempt at a comprehensive software application that performs automatic calculations for nuclear medicine and radiopharmacy, thus 
reducing errors and improving efficiency and accuracy. The associated database allows results to be stored and reports generated. The software is useful, user-friendly, and customizable. We welcome inquiries and suggestions from radiopharmacy and nuclear medicine professionals all over the world, and we will continue to extend and improve the software. The installation program for Nucleolab can be downloaded at www.radiofarmacia.org/nucleolab-english.

\section{REFERENCES}

1. Du Bois D, Du Bois EF. Clinical calorimetry: tenth paper-a formula to estimate the approximate surface area if height and weight be known. Arch Intern Med. 1916;17:863-871.

2. Bell EG, Mc Afee JG, Subramanian G. Radiopharmaceuticals in pediatrics. In: James AE, Wagner HN, Cooke EC, eds. Pediatric Nuclear Medicine. Philadelphia, PA: Saunders; 1974.

3. Lassmann M, Biassoni L, Monsieurs M, Franzius C, Jacobs F. The new EANM pediatric dosage card. Eur J Nucl Med Mol Imaging. 2007;34:796-798.

4. Recommended method for indium-111 platelet survival studies. International Committee for Standardization in Hematology. Panel on Diagnostic Application of Radioisotopes in Hematology. J Nucl Med. 1988;29:564-566.

5. Lötter MG, Heyns Ad, Badenhorst PN, et al. Evaluation of mathematic models to assess platelet kinetics. J Nucl Med. 1986;27:1192-1201.

6. Recommended method for radioisotope red-cell survival studies. International Committee for Standardization in Haematology. Br J Haematol. 1980;45: $659-666$.
7. Recommended methods for measurement of red-cell and plasma volume. International Committee for Standardization in Haematology. J Nucl Med. 1980;21: 793-800.

8. Interpretation of measurement red cell mass and plasma volume in adults. Expert Panel on Radionuclides of the International Council for Standardization in Haematology. Br J Haematol. 1995;89:748-756.

9. Sapirstein LA, Vidt DG, Mandel MJ, Hanusek G. Volumes of distribution and clearances of intravenously injected creatinine in the dog. Am J Physiol. 1955; 181:330-336.

10. Tauxe WN, Maher FT, Taylor WF. Effective renal plasma flow: estimation from theoretical volumes of distribution of intravenously injected ${ }^{131} \mathrm{I}$ orthoiodohippurate. Mayo Clin Proc. 1971;46:524-531.

11. Russell CD, Taylor A, Eshima D. Estimation of technetium-99m-MAG3 plasma clearance in adults from one or two blood samples. J Nucl Med. 1989;30:19551959.

12. Bubeck B, Piepenburg R, Grethe U, Ehrig B, Hahn K. A new principle to normalize plasma concentrations allowing single-sample clearance determinations in both children and adults. Eur J Nucl Med. 1992;19:511-516.

13. Ham HR, Piepsz A. Estimation of glomerular filtration rate in infants and children using a single plasma sample method. J Nucl Med. 1991;32: 1294-1297.

14. Mistry R. Manual of Nuclear Medicine Procedures. London, U.K.: Chapman and Hall; 1988:27-35.

15. Truniger B, Donath A, Kappeler M. Simplified clearance techniques. Helv Med Acta. 1968;34:116-119.

16. Gault MH, Dossetor JB. Evaluation of renal function without collection of urine. Ann Intern Med. 1968;69:26-30.

17. Heck LL, Duley JW. Statistical considerations in lung imaging with Tc-99m albumin particles. Radiology. 1974;113:675-679.

18. Hidalgo JU, Wright RM, Wooten MM. Prediction of technetium-99m yield from molybdenum-99 generators. J Nucl Med. 1967;8:426-429. 